\title{
Mycotoxin production from fungi isolated from grapes
}

\author{
L. Abrunhosa1, R.R.M. Paterson², Z. Kozakiewicz ${ }^{2}$, N. Lima1 and A. Venâncio ${ }^{1}$ \\ ${ }^{1}$ Centro de Engenharia Biológica-IBQF, Universidade do Minho, Braga, Portugal, and ${ }^{2}$ CABI Bioscience UK \\ Centre, Egham, UK
}

2000/74: received 9 January 2001 and accepted 11 January 2001

L. ABRUNhOSA, R.R.M. PATERSON, Z. KOZAKIEWICZ, N. LIMA AND A. VENÂNCIO. 2001.

Aims: In order to assess the potential for producing mycotoxins, fungi were isolated from wine producing grapes.

Methods and Results: The isolates were identified and Penicillium expansum, the most well recognized mycotoxin producer, was analysed for mycotoxin production by TLC. Many of the strains produced patulin and/or citrinin, often depending on whether they were grown on a grape or yeast extract sucrose media.

Conclusions: Citrinin was produced by all strains grown in the yeast extract sucrose medium, but only one strain (from 51) was able to produce this compound in grape juice medium.

Patulin was produced in the yeast extract medium by 20 strains and in grape juice medium by 33 strains.

Significance and Impact of the Study: The presence of mycotoxins in wine producing grapes is discussed. Grapes contamination with patulin seems not to contribute to wine contamination, and no ochratoxin producing fungi was identified.

\section{INTRODUCTION}

There is increasing concern about the presence of mycotoxins in commodities. These compounds are produced by particular species of fungi. Patulin (Scott et al. 1977) and ochratoxin A (Majerus and Otteneder 1996; Zimmerli and Dick 1996) are mycotoxins that have been reported in grapes and grape products such as wine. However, ochratoxin A has not recently been found in Portuguese wine (Festas et al. 2000). Patulin is produced most notably by the fruit-rotting fungus, $P$. expansum, whereas ochratoxin $\mathrm{A}$ is associated with Penicillium verrucosum and Aspergillus ochraceus. Patulin causes gastrointestinal problems, skin rashes, and is known to be mutagenic. Ochratoxin $\mathrm{A}$ is carcinogenic and the European Union is considering imposing regulatory limits in wine. Patulin has been demonstrated to be present in apple and grape juices (Scott et al. 1977; Moss 1998), although it is absent from ciders as it is degraded by the fermentation process. There is a recommended limit for patulin in apple juice in the UK of $50 \mu \mathrm{g} \mathrm{l^{-1 }}$. Citrinin is also produced by Penicillium expansum, but was not found in apple and grape juices (Scott et al. 1977). The production of grapes and products such as wine is important to the Portuguese

Correspondence to: Prof. A. Venâncio, Centro de Engenharia Biológica-IBQF, Universidade do Minho, Campus de Gualtar, 4710-057 Braga, Portugal

(e-mail:avenan@deb.uminho.pt). economy and to countries which import these commodities. Port wine is a particularly important export commodity and is produced from grapes from the Douro region of Portugal. This paper reports on work to isolate fungi from grapes from two wine-producing regions of Portugal, and to analyse recognized mycotoxin-producing fungi to assess the potential for mycotoxin contamination of wine.

\section{MATERIALS AND METHODS}

\section{Grape sampling and preparation}

Grapes were harvested from three vineyards from Ponte do Lima in the Vinhos Verdes region, and a vineyard from Vila Nova de Foz Côa in the Douro region. Sampling took place in mid-August in the Vinhos Verdes region when the first signs of fungal invasion can be observed. Samples were also taken in late September or the first days of October, corresponding to the harvest time of the 1999 season in the Vinhos Verdes and Douro regions. A vineyard of high altitude was selected for the Douro region samples; the conditions are not optimal for Port wine but the greatest mould growth is observed here. Grapes with and without visual signs of fungal invasion were harvested.

Fungi were isolated from the skins and interiors of the grapes (the pulp). Each grape surface was sterilized for 2 min in sodium hypochloride, containing $0.4 \%$ available 
chloride, and washed twice with sterile distilled water. The skin sterilization steps were checked for efficacy by pressing onto Dichloran Rose Bengal Chloramphenicol (DRBC) (Oxoid) and on Dichloran Rose Bengal Yeast Extract Sucrose (DRYES) both supplemented with chloramphenicol $(0 \cdot 01 \%(w / v))$ (Frisvad 1983).

The pulp was separated from the skin under aseptic conditions and then macerated in $1 \mathrm{ml}$ sterile solution of $0 \cdot 1 \%(\mathrm{w} / \mathrm{v})$ peptone. This was vigorously shaken in a vortex for $1 \mathrm{~min}$. Macerated pulp $(0 \cdot 2 \mathrm{ml})$ was plated onto DRBC and DRYES. The macerated pulp was diluted $(10 \times)$ with $0 \cdot 1 \%$ peptone solution and plated out, as above, if numbers of fungi were too high to count.

For skin analysis, intact grapes were cut under aseptic conditions and treated as described above, but without the sterilization step. In this set of experiments, dilutions of $10^{-2}$ and $10^{-3}$ were plated on DRBC and DRYES as described for macerated pulp.

Grapes from each vineyard that had visual signs of fungal growth (rotten) were also analysed. These grapes were cut and macerated with $0 \cdot 1 \%$ peptone solution as above. Dilutions of $10^{-4}$ and $10^{-5}$ were plated onto DRBC and DRYES. All plates were incubated at $25^{\circ} \mathrm{C}$ in the dark.

\section{Isolation and identification of fungal species}

Fungal colonies were transferred to individual slants of Malt Extract Agar 1 (Oxoid) as they became visible at $4 \times$ magnification. This medium was also used to maintain the isolates at $4^{\circ} \mathrm{C}$. Taxonomic identification of all isolates was achieved through macroscopic and microscopic observation in accordance with guidelines published for each genus. The identification of the penicillia strains was made according to
Pitt (1979). Five of the identified species were confirmed and deposited at CABI Bioscience (Egham, UK). Most of the strains have been deposited in the Micoteca da Universidade do Minho (Braga, Portugal) culture collection.

\section{Metabolite production by $\boldsymbol{P}$. expansum}

All P. expansum strains were grown on two media: yeast extract sucrose (YES) medium and a grape juice (GJ) medium $(1 \mathrm{~kg}$ grapes were crushed in 1 litre distilled water and boiled for $2 \mathrm{~h}$. The grape extract was filtered and sterilized by autoclaving, then $15 \mathrm{~g}$ agar were dissolved in $800 \mathrm{ml}$ distilled water and autoclaved. GJ medium was prepared by mixing $200 \mathrm{ml}$ grape extract with the $800 \mathrm{ml}$ agar solution). The cultures were analysed by removing agar plugs, as described in Paterson and Bridge (1994). Thin layer chromatography was undertaken in a saturated chamber, using silica gel 60 TLC plates without indicator (Merck) and a TEF solvent system (toluene, ethyl acetate and formic acid, 5:4:1). The spray reagent was either MBTH (3-methyl-2-benzothiazoline hydrazone hydrochloride, $5 \mathrm{~g} \mathrm{l}^{-1}$ ) with heating for $15 \mathrm{~min}$ at $110^{\circ} \mathrm{C}$, or $p$-anisaldehyde $(0.5 \% \mathrm{v} / \mathrm{v})$ with heating for $8 \mathrm{~min}$ at $105^{\circ} \mathrm{C}$. Griseofulvin, patulin and ochratoxin A (all Sigma) were used as standards.

\section{RESULTS AND DISCUSSION}

Eight genera were isolated from the grapes (Table 1). Penicillium, Cladosporium and Botrytis prevailed in the Douro region and Cladosporium and Botrytis were dominant in the Vinhos Verdes region. One Aspergillus strain was identified from white grapes from the Douro region, although it is was not identified to the species level and
Table 1 Fungi isolated from the most representative white and red castes from Vinhos Verdes and Douro regions (percentage indicated in brackets)

\begin{tabular}{|c|c|c|c|c|}
\hline \multirow[b]{2}{*}{ Fungi } & \multicolumn{2}{|c|}{ Vinhos Verdes } & \multicolumn{2}{|l|}{ Douro } \\
\hline & White castes & Red castes & White castes & Red castes \\
\hline Alternaria spp. & $5(12 \%)$ & $6(18 \%)$ & $4(3 \%)$ & $2(3 \%)$ \\
\hline Aureobasidium pullulans & $2(5 \%)$ & 0 & $4(3 \%)$ & $5(7 \%)$ \\
\hline Aspergillus spp. & 0 & 0 & $1(1 \%)$ & 0 \\
\hline Botrytis spp. & $11(27 \%)$ & $9(26 \%)$ & $45(35 \%)$ & $23(30 \%)$ \\
\hline Cladosporium spp. & $12(29 \%)$ & $12(35 \%)$ & $32(25 \%)$ & $23(30 \%)$ \\
\hline Fusarium spp. & $6(15 \%)$ & $6(18 \%)$ & $3(2 \%)$ & $1(1 \%)$ \\
\hline Penicillium spp. & $5(12 \%)$ & $1(3 \%)$ & $40(30 \%)$ & $22(29 \%)$ \\
\hline P. aurantiogriseum & 0 & 0 & 0 & 1 \\
\hline P. brevicompactum & 1 & 0 & 8 & 1 \\
\hline P. expansum & 0 & 0 & 31 & 20 \\
\hline P. glabrum & 0 & 1 & 0 & 0 \\
\hline P. minioluteum & 0 & 0 & 1 & 0 \\
\hline P. spinulosum & 3 & 0 & 0 & 0 \\
\hline P. thomii & 1 & 0 & 0 & 0 \\
\hline Tricothecium roseum & 0 & 0 & $1(1 \%)$ & 0 \\
\hline Total & $41(100 \%)$ & $34(100 \%)$ & $130(100 \%)$ & $76(100 \%)$ \\
\hline
\end{tabular}


was not tested for mycotoxin production. However, it was not considered to be A. flavus or A. ochraceus, which produce aflatoxins and ochratoxin A, respectively. Penicillium expansum was identified only from the Douro region and was isolated in large amounts from white and red grapes. The grapes were collected from vineyards that may be used to produce Port. It is interesting to note that $P$. expansum was not isolated from the Vinho Verde grapes. This may be due to the fact that the weather conditions during this season were poor, and heavy Botrytis infection was observed. It is known that the cultural conditions for the two varieties are significantly different, and as the Vinho Verde grapes are also more acidic, these conditions may not be conducive to the otherwise ubiquitous $P$. expansum.

Each strain was different in its capacity to produce patulin and/or citrinin, depending on whether it was grown on GJ or YES (Table 2). A small percentage (20\%) of $P$. expansum isolates were positive for patulin on YES agar, whereas they were all positive for citrinin. Citrinin is recognizable as a green streak with a $\mathrm{Rf}$ of 34 . When growing on GJ medium, a higher percentage $(65 \%)$ of isolates were positive for patulin and only one strain was positive for citrinin. The difference is probably due to the chemical composition of the media. This situation is similar to that in apple juice and grape products in which citrinin is not formed or is unstable (Scott et al. 1977), although patulin is common. It would be interesting to test the non-producing strains for potential patulin production with the gene probe for the patulin metabolic pathway reported in Paterson et al. (2000). A metabolite reported in Abo-Dahab et al. (1996) from $P$. expansum was similar to ochratoxin A. However, analysis undertaken here indicated that ochratoxin $\mathrm{A}$ has a higher Rf value than this metabolite, hence confirming that it was not ochratoxin A. The isolation of $P$. brevicompactum is interesting as this fungus was isolated frequently in a study on apples in the $\mathrm{UK}$, although $P$. expansum was more common (Paterson et al. 2000). When DNA from the P. brevicompactum isolates was gene-probed for the patulin metabolic pathway, a PCR product(s) was detected. However, patulin (and citrinin) was not detected, as was the case in the present study. As would be expected, ochratoxin A was not detected. A report of ochratoxin A from a $P$. brevicompactum strain in

Table 2 and citrinin production by the 51 strains Penicillium expansum grown in two different media

\begin{tabular}{clllll}
\hline & \multicolumn{2}{l}{ GJ medium } & & \multicolumn{2}{l}{ YES medium } \\
\cline { 2 - 3 } \cline { 6 - 6 } Number of strains & Patulin & Citrinin & & Patulin & Citrinin \\
\hline $10(20 \%)$ & + & - & + & + \\
$1(2 \%)$ & + & + & - & + \\
$22(43 \%)$ & + & - & & - & + \\
$18(35 \%)$ & - & - & & + \\
\hline
\end{tabular}

Paterson and Kemmelmeier (1989) requires confirmation by other techniques using the same strain. The cultures were positive for brevianamide A in YES and GJ media.

In conclusion, ochratoxin A-producing fungi were not isolated from the grapes. However, it appears that patulin contamination of Douro grapes may be a possibility. The observation that $P$. expansum was not isolated from Vinho Verde grapes is interesting but requires further investigation; it may be due to different cultivation and environmental factors.

\section{ACKNOWLEDGEMENTS}

The British Council and Conselho de Reitores das Universidades Portuguesas (CRUP) Windsor Programme (grant no. 29/00) for promotion of collaboration between UK and Portuguese scientists, and Adega Cooperativa de Ponte do Lima for collaborating in grape sampling, are gratefully acknowledged.

\section{REFERENCES}

Abo-Dahab, N.F., Paterson, R.R.M. and Razak, A.A. (1996) Effect of fungistatic agent 2-deoxy-D-glucose on mycotoxins from Penicillium expansum. Letters in Applied Microbiology 23, 174-178.

Festas, I., Guimarães, F., Herbert, P. et al. (2000) Ochratoxin A in some Portuguese Wines: method validation and screening in Port wine and Vinho Verde. American fournal of Enology and Viticulture 51, 150-154.

Frisvad, J.C. (1983) A selective and indicative medium for groups of Penicillium viridicatum producing different mycotoxins in cereals. Fournal of Applied Bacteriology 54, 409-416.

Majerus, P. and Otteneder, H. (1996) Nachweis und Vorkommen von Ochratoxin A in Wein und Traubensaft. Deutsche LebensmittelRundschau 92, 388-390.

Moss, M.O. (1998) Recent studies of mycotoxins. Fournal of Applied Microbiology Symposium Supplement 84, 62S-76S

Paterson, R.R.M., Archer, S., Kozakiewicz, Z., Lea, A., Locke, T. and O'Grady, E. (2000) A gene probe for the patulin metabolic pathway with potential for use in patulin and novel disease control. Biocontrol Science and Technology 10, 509-512.

Paterson, R.R.M. and Bridge, P.D. (1994) Biochemical Techniques for Filamentous Fungi. IMI Techniques Series no. 1. Wallingford, UK: CABI.

Paterson, R.R.M. and Kemmelmeier, C. (1989) Gradient highperformance liquid chromatography using alkylphenone retention indices of insecticidal extracts of Penicillium strains. Fournal of Chromatography 483, 153-168.

Pitt, J.I. (1979) The Genus Penicillium and its Teleomorphic States Eupenicillium and Talaromyces. London: Academic Press.

Scott, P.M., Fuleki, T. and Harvig, J. (1977) Patulin content of juice and wine produced from moldy grapes. Fournal of Agriculture and Food Chemistry 25, 434-437.

Zimmerli, B. and Dick, R. (1996) Ochratoxin A in table wine and grape-juice: occurrence and risk assessment. Food Additives and Contaminants 13, 655-668. 